Jüvenil idiyopatik artritli hastalarda temporomandibular eklem tutulumu ve ağız diş sağlığı bulguları

\section{Oral health and temporomandibular joint involvement of patient with juvenile idiopathic arthritis}

\section{Dr. Öğr. Üyesi Figen Eren Giray}

Marmara Úniversitesi, Diş Hekimliği Fakültesi, Pedodonti A.D., İstanbul

Doç. Dr. Başak Durmus

Marmara Üniversitesi, Diş Hekimliği Fakültesi, Pedodonti A.D., İstanbul

\section{Dr. Ferhan Ertuğral}

Serbest Uzman Dişhekimi, İstanbul

Doç. Dr. Müferet Ergüven

Medeniyet Üniversitesi, Göztepe Eğitim Araștırma Hastanesi, Çocuk Sağlığı ve Hastalıkları A.D., Çocuk Romatoloji Bölümü, İstanbul

Prof. Dr. ilknur Tanboğa

Marmara Üniversitesi, Diş Hekimliği Fakültesi, Pedodonti A.D., İstanbul

Geliş tarihi: 16 Mart 2018

Kabul tarihi: 26 Haziran 2018

doi: 10.5505/yeditepe.2018.55265

\section{Yazışma adresi:}

Dr. Öğr. Üyesi Figen EREN GiRAY

Marmara Üniversitesi, Diş Hekimliği Fakültesi

Bassbüyük Kampüsü, 34854, Maltepe-istanbul

Tel: 00902164211621 / 05332649887

Fax: 0090216421029

E-posta: erenfigen@yahoo.com,

figen.eren@marmara.edu.tr
ÖZET

Amaç:Bu çalışmanın amacı, İstanbul'daki büyük bir eğitim-araştırma hastanesine gelen ve JIA teşhisi konmuş çocuk hastaların ağız ve diş sağlığı durumlarını ve TME tutulumlarını değerlendirmek ve yaş ile cinsiyet eşleşmesi yapılmış sağlıklı çocuklar ile karşılaştırmaktır.

Gereç ve Yöntem:Araştırmada, JIA teşhisi konmuş 35 çocuk hasta ile yaş ve cinsiyet eşleşmesi yapılmış 35 sağlıklı çocuk dahil edilmiştir. Yapılan muayenede demografik verilerin yanında çürük indeksi (DMFT ve dmft), TME bulguları (disfonksiyon, ağrı, ses, kısıtlı hareket), yüz karakteristikleri (mikrognati, retrognati, anterior open-bite) ve ilaç tedavileri kaydedilmiştir. Oral hijyen, 3 standart epidemiyolojik indeks (gingival index, plak indeksi ve oral temizlik indeksi) ile değerlendirilmiştir.

Bulgular:Çalışma yaşları 6 ile 16 arasında değişmekte olan, 28'i (\%40) erkek ve 42'si (\%60) kız olmak üzere toplam 70 çocuk üzerinde yapıımıștır. Çocukların yaş ortalaması $10,28 \pm 3,49$ yıldır. JIA grubu ile kontrol grubu arasında çürük açısından istatistiksel olarak anlamlı bir farklılık bulunmamak tadır. JIA grubunda kontrol grubuna göre yüksek oranda ağrı, ses ve kısıtlı hareket gözlenmiş, ancak aralarındaki fark istatistiksel olarak anlamlı bulunmamıştır. JIA grubunun gingival indeks düzeyi, kontrol grubundan istatistiksel olarak anlamlı düzeyde yüksek bulunmuştur.

Sonuç:Bu sonuçlar, JIA' nın multidisipliner yönetiminde düzenli ağız-diş sağlığı hizmetinin rolünü vurgulamaktadır.

Anahtar kelimeler: Jüvenil idiyopatik artrit, ağız-diş sağlığı, temporomandibular eklem

\section{SUMMARY}

Aim: The aim of this study was to evaluate the oral health conditions and TMJ involvement of the children diagnosed with JIA attending an education and research hospital in Istanbul and to compare them with age and gender matched healthy controls.

Materials and Methods:The study included 35 children diagnosed with JIA and 35 age- and sex-matched healthy controls. In addition to demographic data, dental caries index (DMFT and DMFT), TMJ abnormalities (dysfunction, pain, voice, restricted movement), facial characteristics (micrognathia, retrognathia, anterior open bite) and used drug were recorded. Oral hygiene was assessed with 3 standard epidemiological indices (gingival index, plaque index and oral hygiene index).

Results:The study was conducted on 70 children, aged between 6 to 16, 28 (\%40) male and 42 (\%60) female. The mean age of the children was $10.28 \pm 3.49$ years. There was no statistically significant difference between the JIA group and the control group in terms of caries. According to the control group, JIA group showed higher rates of pain, voice and restricted movement, but the differences between the groups were not found statistically significant. The gingival index level of the JIA group was found statistically significant- 
ly higher than the control group.

Conclusion:These results emphasize the role of regular oral and dental health care in the multidisciplinary management of JIA.

Key words: Juvenile idiopathic arthritis, oral health, temporomandibular joint

\section{GiRiş}

Juvenil İdiopatik Artrit (JIA), Jüvenil Romatoid Artrit (JRA) veya Jüvenil Kronik Artrit (JKA) olarak da bilinen ve her iki eski tanımı da ortak olarak kapsayan, çocukluk çağının en sık görülen romatolojik hastalığı olup etiyolojisi kesin olarak bilinmemektedir.? Görülme sıklığı ülkeden ülkeye farklııklar göstermektedir. Ülkemizde yapılan bir çalışmada JIA prevalansı 64/100 000 olarak bildirilmiştir. ${ }^{2}$

JIA, tekil bir hastalık olmaktan çok çeşitli klinik tabloların bir arada görülebileceği bir hastalıklar toplamıdır. ${ }^{3}$ Çocukluk çağında başlayan, bir veya daha fazla eklemin sürekli enflamasyonu ile karakterize, otoimmün enflamatuar bir hastalıktır. Farklı genetik, immünolojik ve klinik özellikler ile (ağrı, eklemlerde şişlik, ısı artışı, kızarıklık ve hareket kısıtlılığı, yorgunluk gibi) alt gruplara ayrılmaktadır. Kısıtlı fiziksel aktivitenin yanında ağrı, JIA' lı bireylerde hayat kalitesini etkileyen en önemli semptom olarak bildirilmiştir. ${ }^{4}$ JIA'da diğer eklemlerin yanında temporomandibular eklem (TME) de çoğunlukla etkilenmektedir. ${ }^{5}$ Gelişimi devam eden bireylerde Temporomandibular eklem rahatsızlıkları (TMR), dentofasiyal büyüme ve gelişmeyi etkileyerek mikrognati, retrognati, yüz asimetrisi ve anterior açık kapanış gibi yüz gelişiminde değişikliklere neden olabilmektedir., ${ }^{6,7}$ Ayrıca ağız açma zorluğuna, çiğneme fonksiyonlarında kısıtlamalara ve ağız sağlığının devam ettirilmesinde güçlüklere yol açabilmektedir. ${ }^{8}$

Üst ekstremite ve ellerin etkilenmesi doğru ve etkili ağız hijyeninin sağlanmasını (diş fırçalama, diş ipi kullanma gibi) zorlaştırabilmekte, tedavide kullanılan ilaçların yüksek oranda şeker içermesi ise, çürük riskini arttırmaktadır. ${ }^{9}$ Yapılan araştırmalarda JIA görülen bireylerde, tamponlama kapasitesinde değişiklik, inorganik komponentlerde (kalsiyum, fosfat, potasyum, sodium, klorid vb) ve immün ve antimikrobiyal faktörlerde (IgA ve lizozim) azalma gibi tükürük içeriğinde değişiklikler meydana geldiği bildirilmiştir. ${ }^{10-12}$ Ağız sağlığı, özellikle hastalık döneminde, kortikosteroidlerin ve anti-romatizmal ilaçların kullanımı ile bağışıklık sisteminin bastırıldığı durumlarda önem taşımaktadır. Kötü diş ve diş eti sağlığı, sistemik enfeksiyonlar için risk faktörleridir. ${ }^{13}$ JIA ve ağız sağlığı ile ilgili birçok araştırma yapılmış ve farklı sonuçlar ortaya çıkmıştır.

Yapılan literatür taramasında, JIA'lı hastalarda ağız diş sağlığı ve temporomandibular eklem disfonksiyonunu (TMD) birlikte değerlendiren fazla çalışmaya rastlanmamıştır. Bu nedenle, bu çalışmanın amacı, 6-16 yaş arası JIA görülen çocuklarda ağız diş sağlığını değerlendirmek ve TME et- kilenmesini gözlemlemek, yaş ve cinsiyet eşleşmesi yapılmış sağlıklı bir çocuk grubu ile karşılaştırmaktır.

\section{GEREÇ VE YÖNTEM}

Bu çalışma, Helsinki Deklarasyonu Prensipleri' ne uygun olarak yapıldı. Çalışmaya başlamadan önce, çalışma ile ilgili Marmara Üniversitesi Diş Hekimliği Fakültesi Klinik Araştırmalar Etik Kurul Komitesi' nden etik kurul onayı (Karar No: 2017-90) ve katılımcı ile velilerinden imzalı "Bilgilendirilmiş Olur Formu" alındı.

\section{Hasta Seçimi}

Araştırmada, Medeniyet Üniversitesi Göztepe Eğitim Araştırma Hastanesi, Çocuk Sağlığı ve Hastalıkları Anabilim Dalı, Çocuk Romatoloji Bölümü' nde ILAR (The International League of Associations for Rheumatology) sistemine göre (Petty et al. 1998) JIA teşhisi konmuş ve yaşları 6-16 arasında değişen çocukların TME bulguları ve ağız-diş sağlığı bulguları değerlendirildi. Kontrol grubu olarak ise yine aynı hastanenin Çocuk Sağlığı ve Hastalıkları Anabilim Dalı' na rutin kontroller için gelen ve JIA grubundaki çocuklar ile yaş ve cinsiyet eşleşmesi yapılmış sağlıklı çocuklar dahil edildi. Hastalığın remisyon döneminde olan, temporomandibular rahatsızlık (TMR) nedeni ile herhangi bir tedavi görmüş veya görmekte olan ve koopere olmayan çocuklar çalışmaya dahil edilmedi.

\section{Klinik Muayene}

Ağız içi klinik muayene ve TME muayenesi, çocukların rutin kontrol altında bulundukları hastanenin polikliniğinde, gün ışığında ağız içi ayna ve periodontal sond kullanılarak 3 deneyimli çocuk dişhekimi tarafından (F.E.G, B.D. ve F.E.) yapıldı. Dişler muayeneden önce fırçalanmadı, ancak herhangi bir yiyecek artığı görülmesi durumunda sond veya pamuk tamponla temizlendi. Çürük lezyonlarının tanısı gözle yapıldı ve radyografi alınmadı. Muayene sırasında yaş ve cinsiyetin yanı sıra JIA tedavisinde kullanılan ilaçlar da kaydedildi. Çürük değerlendirmesinde Dünya Sağlık Örgütünün (WHO) tanımlarına uygun dmft ve DMFT indeksleri kullanıldı. ${ }^{14}$

Oral hijyen, önceki çalışmalar rehber alınarak 3 standart epidemiyolojik indeks ile değerlendirildi. Gingival indeks: $1=$ Normal gingiva, enfeksiyon yok, renklenme ve kanama yok, 2=Hafif enfeksiyon, hafif renk değişimi, basınca bağlı kanama yok, 3=Orta enfeksiyon, eritem var, basınca bağlı kanama var, 4=ileri düzeyde enfeksiyon, spontan kanama şeklinde skorlandı. Plak indeksi skorlaması: 0=Plak yok, 1=Dişler temiz görünümlü, dişin gingival $1 / 3^{\prime}$ ünde sond ile temizlenebilen plak var, 2=Çıplak gözle görülen, birikmiş plak var, $3=$ =işeti ve diş yüzeyi arasında yumuşak plak birikimi var şeklinde yapıldı. Oral temizlik indeksi ise: $0=$ $2 / 3^{\prime}$ ten daha fazla yüzeyde plak birikimi, $2=2 / 3-1 / 3$ yüzeyde plak birikimi, $4=1 / 3^{\prime}$ ten az yüzeyde plak birikimi, $6=\mathrm{Di}$ - 
şeti marjinalinde ince devamlı bant şeklinde plak birikimi, $8=$ Çok hafif, aralıklı plak birikimi, $10=$ Plak yok şeklinde skorlandı. Karışık dişlenme döneminde olan çocuklarda karışıklıktan kaçınmak amacı ile her çocukta altı diş, (16, $26,36,46,11$ ve 31 nolu dişler) indeks dişleri olarak tanımlandı. Bu dişlerin dört düz yüzeyi için ayrı skorlamalar yapıldı ve daha sonra ortalamaları tek değer olarak kaydedildi.13

TME muayenesi ve yüz karakteristiklerinin değerlendirilmesinde önceki çalışmalar rehber alınarak yapıldı ve muyene sırasında TME de disfonksiyon, ağrı, ses ve kısıtlı hareket varlığı değerlendirildi. Ayrıca mikrognati, retrognati, fasiyal asimetri ve anterior open-bite değerlendirmesi yapılarak kaydedildi. ${ }^{15,16}$

\section{İstatistiksel analiz}

Çalışmada elde edilen bulgular değerlendirilirken, istatistiksel analizler için IBM SPSS Statistics 22 (IBM SPSS, Türkiye) programı kullanıldı. Çalışma verileri değerlendirilirken parametrelerin normal dağılıma uygunluğu Kolmogorov-Smirnov ve Shapiro Wilks testleri ile değerlendirildi. Normal dağılım gösteren parametrelerin iki grup arası karşılaştırmalarında Student t test, normal dağılım göstermeyen parametrelerin iki grup arası karşılaştırmalarında Mann Whitney U test kullanıldı. Niteliksel verilerin karşılaştırılmasında ise Ki-Kare testi ve Fisher's Exact Ki-Kare testi kullanıldı. Anlamlılık $p<0,05$ düzeyinde değerlendirildi.

\section{BULGULAR}

Çalışma yaşları 6 ile 16 arasında değişmekte olan, 28'i (\%40) erkek ve 42'si (\%60) kIz olmak üzere toplam 70 çocuk üzerinde yürütüldü. Çocukların yaş ortalaması $10.28 \pm 3.49$ yıldır. Grupların DMFT, dmft, DMFS ve dmfs değerleri Tablo 1'de görülmektedir. JIA grubu ile kontrol grubu arsında, DMFT, dmft, DMFS ve dmfs sayıları açısından istatistiksel olarak anlamlı bir farklılık bulunmadı ( $p>0.05)$.

Tablo 1. Grupların DMFT, dmft, DMFS ve dmfs açısından değerlendirilmesi

\begin{tabular}{lccc} 
& \multicolumn{1}{c}{ JA } & Kontrol & \\
\cline { 2 - 3 } & Ort \pm SS (medyan) & Ort \pm SS (medyan) & p \\
\hline \hline DMFT & $3,2 \pm 3,19(3)$ & $3,29 \pm 4(2)$ & 0,727 \\
dmft & $2,79 \pm 3,55(1,5)$ & $3,74 \pm 4,9(2)$ & 0,742 \\
DMFS & $4,17 \pm 4,46(3)$ & $4,49 \pm 6,07(3)$ & 0,727 \\
dmfs & $5 \pm 7,77(1,5)$ & $7,09 \pm 10,49(3)$ & 0,718 \\
\hline
\end{tabular}

Ağız hijyeni değerlendirilmesinde gruplar arasında plak indeksi ve oral temizlik indeksi düzeyleri açısından istatistiksel olarak anlamlı bir farklıık bulunmamaktadır belirlenmedi ( $p>0.05$ ). Bunun yanında JIA grubunun gingival indeks düzeyi, kontrol grubundan istatistiksel olarak anlamlı düzeyde yüksek bulundu (p:0.002; $p<0.05)$ (Tablo 2).
Tablo 2. Grupların oral hijyen indeksleri açısından değerlendirilmesi

\begin{tabular}{lccc}
\hline & JIA & Kontrol & \\
\cline { 2 - 3 } & Ort \pm SS (medyan) & Ort \pm SS (medyan) & p \\
\hline \hline Gingival indeksi & $2 \pm 0,8(2)$ & $1,43 \pm 0,7(1)$ & $0,002^{*}$ \\
Plak indeksi & $1,23 \pm 0,84(1)$ & $1,26 \pm 0,74(1)$ & 0,731 \\
Oral temizlik indeksi & $5,77 \pm 3,1(6)$ & $5,43 \pm 2,68(6)$ & 0,574 \\
\hline
\end{tabular}

JIA grubu ile kontrol grubunda yer alan bireyler TMR ve yüz karakteristikleri açısından değerlendirildiğinde olguların hiçbirinde disfonksiyon, mikrognati ve fasial asimetriye rastlanmadı. JIA grubundaki çocukların \%14,3' ünde ağrı, \%14,3' ünde ses ve \%17,1' inde kısıtlı hareket gözlendi. Eklem bulguları açısından JIA grubu kontrol grubu ile karşılaştırıldığında aralarındaki farkın istatistiksel olarak anlamlı olmadığı görüldü (Tablo 3).

Tablo 3. Grupların eklem bulguları açısından değerlendirilmesi

\begin{tabular}{lccc}
\hline \multirow{2}{*}{ Eklem Bulguları } & JIA & Kontrol & \\
\cline { 2 - 3 } & $\mathbf{n}(\%)$ & $\mathbf{n ~ ( \% )}$ & $\mathbf{p}$ \\
\hline \hline Disfonksiyon & - & - & - \\
Ağrı & $5(\% 14,3)$ & $2(\% 5,7)$ & 0,428 \\
Ses & $5(\% 14,3)$ & $4(\% 11,3)$ & 1,000 \\
Kisıtlı Hareket & $6(\% 17,1)$ & $1(\% 2,9)$ & 0,106 \\
Mikrognati & - & - & - \\
Retrognati & $0(\% 0)$ & $1(\% 2,9)$ & 1,000 \\
Fasial Asimetri & - & - & - \\
Anterior Open-Bite & $1(\% 2,9)$ & $3(\% 8,6)$ & 0,614 \\
\hline Fisher's Fract Test & & &
\end{tabular}

JIA grubunda tedavi amaçıı kullanılan ilaçlar değerlendirildiğinde, olguların \%42,9'unun metotreksat, \%22,9'unun da sulfasalazin kullandığı, ayrıca $\% 48,6$ 'sının folbiol, $\% 45,7$ 'sinin de prednol kullandığı belirlenmiştir.

JIA grubunda kullanılan ilaçlar ile TMR bulgularının görülme sıklığının değerlendirilmesi Tablo 4'te görülmektedir. Buna göre metotreksat, sulfosalazin ve prednol kullanan ve kullanmayan olgular arasında ağrı, ses, kısıtlı hareket, retrognati ve anterior open-bite görülme oranları açısından istatistiksel olarak anlamlı bir farklılık izlenmedi ( $p>0.05)$.

Tablo 4. JIA grubunda Metotreksat, Sulfosalazin ve Prednol kullanımına göre TMR bulgularının görülme sıklığının değerlendirilmesi

\begin{tabular}{|c|c|c|c|c|c|c|c|c|c|}
\hline & \multicolumn{3}{|c|}{ Metotreksat } & \multicolumn{3}{|c|}{ Sulfosalazin } & \multicolumn{3}{|c|}{ Prednol } \\
\hline & $\begin{array}{c}\text { Yok } \\
(\mathrm{n}=20)\end{array}$ & $\begin{array}{c}\text { Var } \\
(\mathrm{n}=15)\end{array}$ & & $\begin{array}{c}\text { Yok } \\
(\mathbf{n}=27)\end{array}$ & $\begin{array}{c}\text { Var } \\
(n=8)\end{array}$ & & $\begin{array}{c}\text { Yok } \\
(\mathrm{n}=19)\end{array}$ & $\begin{array}{c}\text { Var } \\
(\mathrm{n}=16)\end{array}$ & \\
\hline $\begin{array}{l}\text { TMR } \\
\text { Bulguları } \\
\end{array}$ & n (\%) & $\mathrm{n}(\%)$ & p & n (\%) & n (\%) & $\mathbf{p}$ & $\mathrm{n}(\%)$ & n (\%) & p \\
\hline Ağr1 & $\begin{array}{c}2 \\
(\% 10) \\
\end{array}$ & $3(\% 20)$ & 0,631 & $\begin{array}{c}5 \\
(\% 18,5) \\
\end{array}$ & $0(\% 0)$ & 0,315 & $\begin{array}{c}3 \\
(\% 15,8) \\
\end{array}$ & $\begin{array}{c}3 \\
(\% 12,5) \\
\end{array}$ & 1,000 \\
\hline Ses & $1(\% 5)$ & $\begin{array}{c}4 \\
(\% 26,7)\end{array}$ & 0,141 & $\begin{array}{c}4 \\
(\% 14,8) \\
\end{array}$ & $\begin{array}{c}1 \\
(\% 12,5)\end{array}$ & 1,000 & $\begin{array}{c}1 \\
(\% 5,3)\end{array}$ & $4(\% 25)$ & 0,156 \\
\hline $\begin{array}{l}\text { Kisitlı } \\
\text { Hareket }\end{array}$ & $\begin{array}{c}3 \\
(\% 15) \\
(\%\end{array}$ & $3(\% 20)$ & 1,000 & $\begin{array}{c}4 \\
(\% 14,8)\end{array}$ & $2(\% 25)$ & 0,602 & $\begin{array}{c}3 \\
(\% 15,8)\end{array}$ & $\begin{array}{c}3 \\
(\% 18,8)\end{array}$ & 1,000 \\
\hline Retrognati & $0(\% 0)$ & $0(\% 0)$ & - & $0(\% 0)$ & $0(\% 0)$ & - & $0(\% 0)$ & $0(\% \mathbf{0})$ & - \\
\hline $\begin{array}{l}\text { Anterior } \\
\text { Open-Bite }\end{array}$ & $1(\% 5)$ & $0(\% 0)$ & 1,000 & $\begin{array}{c}1 \\
(\% 3,7)\end{array}$ & $0(\% 0)$ & 1,000 & $0(\% 0)$ & $\begin{array}{c}1 \\
(\% 6,3)\end{array}$ & 0,457 \\
\hline
\end{tabular}

Aynı şekilde JIA grubunda kullanılan ilaçlar ile çürük ilişkisi değerlendirildiğinde, metotreksat, sulfosalazin, prednol ve folbiol kullanan ve kullanmayan olgular arasında DMFT, dmft, DMFS ve dmfs ortalamaları arasındaki farkın istatistiksel olarak anlamlı olmadığı görüldü ( $p>0.05$ ) (Tablo 5). 
Tablo 5. JIA grubunda Metotreksat, Sulfosalazin, Prednol ve folbiol kullanımına göre DMFT, dmft, DMFS ve dmfs skorlarının değerlendirilmesi

\begin{tabular}{|c|c|c|c|c|c|c|c|c|c|c|c|c|}
\hline & \multicolumn{3}{|c|}{ Metotreksat } & \multicolumn{3}{|c|}{ Sulfosalazin } & \multicolumn{3}{|c|}{ Prednol } & \multicolumn{3}{|c|}{ Folbiol } \\
\hline & $\begin{array}{c}Y_{0 k} \\
(\mathrm{n}=\mathbf{2 0})\end{array}$ & $\begin{array}{c}\mathrm{Var} \\
(\mathrm{n}=15)\end{array}$ & & $\begin{array}{c}\text { Yok } \\
(\mathbf{n}=27)\end{array}$ & $\begin{array}{c}\mathrm{Var} \\
(\mathrm{n}=8)\end{array}$ & & $\begin{array}{c}\text { Yok } \\
(\mathrm{n}=19)\end{array}$ & $\begin{array}{c}\mathbf{V a r} \\
(\mathrm{n}=16)\end{array}$ & & $\begin{array}{c}\text { Yok } \\
(\mathrm{n}=18)\end{array}$ & $\begin{array}{c}\text { Var } \\
(\mathrm{n}=17)\end{array}$ & \\
\hline & $\begin{array}{c}\begin{array}{c}\text { ortteSS } \\
\text { (medyan) }\end{array}\end{array}$ & $\begin{array}{c}\text { OrttsS } \\
\text { (medyan) }\end{array}$ & $\mathrm{p}$ & $\begin{array}{c}\text { Ort+SS } \\
\text { (medyan) }\end{array}$ & $\begin{array}{c}\text { Ortt+SS } \\
\text { (medyan) }\end{array}$ & $\mathrm{p}$ & $\begin{array}{c}\text { Ortt+5S } \\
\text { (medyan) }\end{array}$ & $\begin{array}{c}\text { OrttsS } \\
\text { (medyan }\end{array}$ & $\mathbf{p}$ & $\begin{array}{c}\text { Ort+SS } \\
\text { (medyan) }\end{array}$ & $\begin{array}{c}\text { OrttSS } \\
\text { (medyan) }\end{array}$ & $\mathbf{p}$ \\
\hline DMFT & 3,4452,2,56(3) & $2.8713,366(2)$ & 0,386 & 3,44+3,32(3) & $2,384,7,2(1,5)$ & 0,47 & & & 0,344 & $3,56+3,03(3)$ & $2,8253,4,(2)$ & 0,381 \\
\hline $\mathrm{dmft}$ & $3.2643,89(2)$ & $2223,1,(1)$ & 0,490 & $2,2713,16(0.5)$ & $4,544,41(3.5)$ & 0.137 & $3,24+947$ & ) & 0.563 & $2,8223,34(0)$ & $2,76+3,35(2)$ & 0.718 \\
\hline DMFS & $1,3 \times 3,67(3.5)$ & $45,56(3)$ & 0,14 & $4,594,69$ (1) & $2,7 \pm+3,41(1,5)$ & 0,307 & 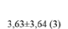 & $181+5,32$ & 0.589 & 4. $44 \pm 3,84(3,5)$ & 3.,83:5.13(3) & 0.419 \\
\hline $\mathrm{dmft}$ & $6.32=92424(2)$ & 3,$335 ; 2,3(1)$ & 0,514 & $3.85 \pm 6.14(0.9)$ & $8,75 \pm 11,37(9)$ & 0,137 & 221.8888 & 626.314 & 0.539 & $5,70609,996(0)$ & $4,24=6.38(2)$ & 0.83 \\
\hline
\end{tabular}

\section{TARTIŞMA}

JIA'nın görülme insidansı ve yaygınlığı, dünyadaki farklı etnik ve coğrafik bölgelere göre değişiklikler göstermektedir. JIA ile ilgili birçok veri, Avrupa ve Kuzey Amerika' da yapılan araştırmalardan elde edilmiştir.17 Yapılan literatür taramalarında, JIA görülen Türk çocuklarının ağız-diş sağlığı bulguları ile ilgili bir çalışmaya rastlanmamıştır. Bu çaış̧mada, JIA görülen Türk çocuklarının ağız diş sağlığı ile TME etkilenmesi değerlendirilmiş ve yaş ile cinsiyet eşleşmesi yapılmış sağlıklı bir çocuk grubu ile karşılaştırılmıştır. JIA' nın sistemik formu hariç, erkek çocuklarında, kız çocuklarına göre daha az sıklıkta görüldüğü bildirilmiştir.18 Ülkemizde yapılan ve Türk çocuklarındaki JIA profilinin araştıııldığı bir çalışmada, erkek ve kızlarda görülme oranları birbirine yakın olarak bildirilmiştir.17 Araştırmamızda ise, incelediğimiz grupta kız çocuklarında görülme oranı \%60 olarak bulunmuştur.

Avrupa ve dünyanın diğer bölgelerinde yapılan araştırmalarda, JIA ve ağız sağlığı ile ilgili farklı sonuçlar elde edilmiştir. 2000 yılında Walton ve ark.'nın yaptıkları literatür derlemesinde, farklı araştırmaların hepsinde ortak sonuç olarak JIA görülen hastalarda çürük oranında artış rapor edilmiştir. ${ }^{9}$ Welbury ve ark.'nın JIA görülen 149 hastanın, yaş ile cinsiyet eşleşmesi yapılmış sağlıkı bireyler ile çürük açısından karşılaştırıldığı araştırmalarında, JIA görülen bireylerde tüm yaş gruplarında diş çürüğünün sağlıklı gruba göre daha yüksek oranda görüldüğü bildirilmiştir. Bu sonuçların, JIA grubundaki hastaların diş çürüğüne daha yatkın olduklarını veya diş sağlığına yönelik engellerinin olabileceğini düşündürdüğünü belirtmişlerdir. Bu engeller arasında, genel sağlık problemlerinin yanında ağız-diş sağlığının daha az önemli görülmesi, tıbbi bakım sırasında ağrılı prosedürlerden kaynaklanan anksiyetenin dental tedaviyi zorlaştırması, TME'nin etkilenmesi nedeniyle ağız açıklığının azalmasına bağlı olarak kişisel ağız hijyeni ve dental tedavilerin yapılabilmesinin zorlaşması sayılmaktadır. ${ }^{13}$ Ahmed ve ark. ${ }^{19}$ tarafından Ingiltere' de yapılan ve yine JIA görülen çocuklardaki ağız sağlığının değerlendirildiği bir araştırmada, çürük açısından sağlıklı çocuklar ile karşılaştırıldığında anlamlı bir fark olmadığı, tedavi edilmeyen çürük sayısında artış olduğu bildirilmiştir. Araştırmaya dahil edilen JIA görülen çocukların ailelerinin büyük çoğunluğunun şeker tüketim sıklığı ile diş çürüğü arasındaki ilişkiyi bildikleri ve çocukların şeker tüketimlerini kısıtladıkları belirtilmiştir. JIA görülen ve daimi dişlenme döneminde olan çocukların, ağız içi durumlarının sağlıklı çocuklar ile karşılaştııldığı bir başka araştırmada, radyografi ile tespit edilmiş arayüz çürüklerini de içeren DMFS değerleri arasında anlamlı bir farlılık olmadığı bildirilmiştir. Aynı araştırmanın anket sonuçlarına göre, JIA'ı bireylerin dişlerini sağlıklı bireylere göre daha özenli fırçaladıkları ve ellerde meydana gelen fiziksel kısıtlamanın diş fırçalama hareketlerini etkilemediği rapor edilmiştir. ${ }^{20}$ Araştırmamızda, çalışmaya dahil ettiğimiz JIA görülen çocuklar ile kontrol grubu arasında, Ahmed ve ark. ve Leksell ve ark. ile benzer olarak DMFT, dmft, DMFS ve dmfs sayıları açısından istatistiksel olarak anlamlı bir farklılık bulunamamıştır ( $p>0.05)$.

Şeker içeren şurup formundaki ilaçların uzun dönem kullanımının çürük riskini arttırdığı bildirilmektedir.21 Bu çalışmaya dahil edilen JIA grubundaki çocukların tedavi amacı ile kullandıkları ilaçların (metotreksat (MTX), sulfosalazin, prednol ve folbiol) diş çürüğü ile ilişkisi değerlendirildiğinde, bu ilaçları kullanan ve kullanmayan bireylerin DMFT, dmft, DMFS ve dmfs sayıları ortalamaları arasında istatistiksel olarak anlamlı bir farklıık olmadığı görülmüştür. MTX ve sulfosalazin ülkemizde şurup olarak değil de tablet formunda bulunmakta ve küçük çocuklarda tablet ezilerek toz haline getirilerek kullanılmaktdır.

Ağız diş sağlığının devam ettirilmesinde önemli bir rol oynayan tükürük, otoimmün hastalıkları da içeren bazı sistemik hastalıkların teşhis edilmesinde kullanılmaktadır. ${ }^{22}$ JIA lı bireylerde tükürük parametrelerinin değerlendirildiği bir araştırmada, stimüle edilmiş tükürükteki antimikrobiyal, remineralizasyon ve lubrikant aktivitelerde azalma ve oral temizlik indeksi ile artmış biofilm akümülasyonu bildirilmiştir. ${ }^{2}$ Başka bir araştırmada, yine sağlıklı bireyler ile karşılaştırıldığında JIA görülen bireylerde plak ile kaplı yüzeylerin oranı ile, sondalamada kanama ve sondalama derinliği değerlerinin yüksek olduğu gösterilmiştir. ${ }^{20}$ Welbury ve ark. JIA'll bireylerde, gingival indeks, plak indeksi ve oral temizlik indekslerini kullanarak yaptıkları ağız hijyeni ve gingival enflamasyon değerlendirmesinde, sağlıklı çocuklara göre, her yaş grubu için indekslerin hepsinde anlamlı artış rapor etmişlerdir. Bu bulguların, ağız açma zorluğuna veya üst ekstremite tutulumuna bağlı olarak fırçalamanın güç olması ile birlikte plak akümülasyonunun artması ile ilgili olabileceği belirtilmiştir. ${ }^{13}$ Ahmed ve ark., ${ }^{19}$ $J I A^{\prime}$ lı bireylerde bakteriyel dental plak ve gingival enflamasyon değerlerini, sağlıkı bireyler ile karşılaştırdıkları araştırmalarında, ortalama plak skorlarında anlamlı bir fark bulamadıklarını bildirirken, hem ortalama gingivitis skorlarında hem de gingival indekste anlamlı derecede yüksek değerler rapor etmişlerdir. Bu çalışmada değerlendirilen gruplarda, plak indeksi ile oral temizlik indekslerinde anlamlı bir fark bulunmazken, gingival indekste, sağlıklı gruba göre anlamlı derecede yüksek skorlar elde edilmiştir. Yüksek gingivitis skorlarının olası sebepleri arasında me- 
totreksat gibi ilaçların kullanılması ve belki de hastalığın kendi sürecine bağlı olarak değișen tükürük özellikleri ile lokal immün yanıt olabileceği bildirilmiştir.19 Ayrıca JIA'ya bağlı olarak ortaya çıkan artmış sinovit aktivitenin, dokuları dolaşan ve yayan enflamatuar mediatörlerin (iltihaplı hücrelerden gelen sitokinler ve matris metalloproteinazlar gibi) miktarını arttırabildiği de bildirilmiştir. ${ }^{20,23}$

JIA da TME'nin tek veya çift taraflı olarak etkilenen ilk ve/veya tek eklem olabileceği bildirilmiştir (24). Yapılan araştırmalarda JIA görülen hastalarda TME tutulum ora$\mathrm{nI}$, araştırmaya dahil edilen JIA alt gruplarına ve teşhiste kullanılan yöntemlere göre \%17-\%87 oranları arasında değişmektedir. ${ }^{16,25}$ TME tutulumunun erken dönemde belirlenmesi önem taşımaktadır. Tanı amacıyla klinik muayene, panoramik radyografi, bilgisayarlı tomografi (BT), kemik taraması, MRG, ultra-sonografi (US) ve üç boyutlu bilgisayarlı tomografi (3-D BT) dahil olmak üzere görüntüleme teknikleri kullanılabilmektedir. ${ }^{26}$ TME inflamasyonunu doğrulamak için altın standart, kontrastlı bir MRG'dir. ${ }^{27}$ Ancak MRG'nin kaynaklarının sınırlı ve pahalı olması, özellikle küçük çocuklarda sedasyon gerekebilmesi gibi dezavantajları vardır. ${ }^{28} \mathrm{Bu}$ dezavantajlar nedeni ile araştırmamızda TMR'nin belirlenmesinde klinik muayene yöntemi kullanılmıştır.

TME tutulumunun klinik özellikleri, mikrognati, retrognati, mandibula asimetrisi, maloklüzyon, ağrı, maksimum ağız açıklığının sınırlandırıması, trismus, maksimum ağız açıklığında sapma, TME'de şişme ve eklem sesleridir. ${ }^{25}$ Abramowicz ve ark, JIA görülen çocuklarda, TME enflamasyonu (sinovitis) ile ilişkili olabilecek fiziksel özellikleri araştırdıkları çalışmalarında, kısıtlanmış maksimum ağız açıkığı ve ağız açmada deviasyonun, TME tutulumu ile ilişkili en yaygın iki klinik belirti olduğunu bulmuşlardır. ${ }^{29}$ Araştırmamızda bu çalışma ile benzer olarak kısıtlanmış ağız açıklığı, diğer TMR klinik bulgularından daha yüksek oranda tespit edilmiştir.

Hu ve ark..$^{16}$ dentofasiyal morfoloji ve oklüzyonu karşılaştırmalı olarak değerlendirdikleri araştırmalarında, JIA görülen çocuklardaki TME semptomunun görülme oranını \%55 olarak bildirmişlerdir. Bu çalışmada ise JIA grubunda, Hu ve ark.' ndan daha düşük olarak \%17 oranında TMR bulgusuna rastlanmıştır. Yine aynı araştırmada ağı şikayetinin \%22 oranında görüldüğü bildirilmiştir. ${ }^{16}$ Diğer araştırmalardan daha düşük olan bu değerin, hastalığın erken dönem teşhisinde etkili ilaç tedavisi sonucunda ağrı görülme sıklığının azaltılabileceğini ve özellikle küçük çocuklarda ağrı değerlendirilmesinin zorluğu ile ilgili olabileceği belirtilmiştir. ${ }^{30}$ Araştırmamızda ağrı şikayeti, JIA grubunda $\% 14,3$ olarak bulunmuştur.

Savioli ve ark. ${ }^{15}$ JIA görülen bireylerde yüz karakteristiklerini değerlendirdikleri araştırmalarında, \%14 oranında anterior açık kapanış ve \%33 oranında konveks yüz profiline rastlamışlardır. Bu bulguların mikrognati ile ilişkili olabile- ceğini belirtmişlerdir. Bu çalışmada Savioli ve ark.' ndan farklı olarak olguların hiçbirinde disfonksiyon, mikrognati ve fasial asimetri görülmemiş ve anterior açık kapanış JIA grubunda yalnızca 1 çocukta $(\% 2,9)$ belirlenmiştir.

JIA grubu ile kontrol grubu arasında TME' de disfonksiyon, ağrı, ses ve kısıtlı hareket varlığı ile yüz karakteristikleri açısından değerlendirildiğinde araştırmamızdaki gruplar arasında anlamlı bir farklılık bulunamamıştır. Küseler ve ark. ${ }^{31}$ yeni teşhis konmuş ${ }^{15} \mathrm{JIA}$ görülen hastada, 2 yıl boyunca klinik muayene ve magnetik rezonans görüntülemesi (MRG) ile TME gelişimini takip etmişlerdir. Araştımanın sonunda ortadan şiddetliye kadar değişen klinik semptomlar görülen hastaların hepsinde MRG'de patolojilere rastladıklarını bildirirken, klinik bulgusu görülmeyen hastaların hepsinin MRG sonuçlarında normal görüntüye rastlanmadığını belirtmişlerdir. Klinik muayenenin filtre olarak kullanılabileceğini ve klinik semptom göstermeyen bireylerin MRG için yönlendirilebileceklerini belirtmişlerdir.

Bu çalışmanın kısıtlamalarından biri, hastalığın alt tipleri ve seyir süreci belirlenmeden sadece JIA teşhisi konmuş ve tedavisi devam eden çocukların ağız diş sağlığı bulgularının değerlendirilmiş olmasıdır. Hastalığın alt tiplerine ve seyir sürecinin uzunluğuna göre bulguların şiddeti de farklılıklar gösterebilmektedir. Frid ve ark., klinik TME tutulumu olan ve olmayan JIA' lı çocukların hastalık aktivitesini, engellilik derecesini ve sağlıkla ilgili yaşam kalitesini değerlendirmişler ve JIA hastalığında TME tutulumunun, hastalık aktivitesi ve engellilik derecesinin yüksek, sağlıkla ilgili yaşam kalitesinin bozuk olması ile ilişkili olduğunu belirtmişlerdir. ${ }^{32}$ Twilt ve ark. ${ }^{33}$ JIA'lı hastalarda TME tutulumu ile ilgili yaptıkları uzun dönemli klinik takipli araştırmalarında, düşük hastalık aktivitesinde, kondildeki değişikliklerin zamanla rejenere olabildiğini belirtmişlerdir. Hastalığın seyir süresi, aktivitesi ve JIA'nın alt tipleri de belirlenerek ağız diş sağlığı ve TME tutulumunun da değerlendirildiği uzun dönemli klinik araştırmalara intiyaç vardır. JIA'nın tıbbi tedavisinin temelini oluşturan ilaçlar içinde en sık kullanılanı non-steroidal anti inflamatuar ilaçlardır (NSAii). NSAii etkili olamadığı durumlarda sulfasalazin veya MTX kullanılmaktadır. MTX, JIA tedavisinde etkinliği kanıtlanmış ve yan etkileri oldukça az gözlenen uzun etkili bir ilaçtır (34). MTX'in poliartiküler tipteki JRA'lı hastalarda, TME üzerindeki etkinliğinin radyografik olarak değerlendirildiği iki farklı araştırmada, MTX kullanımının TME tutulumunu ve kraniofasiyal dismorfolojiyi anlamlı derecede azalttığı bildirilmiştir. ${ }^{35,36}$ Tavşanlarda yapılan bir hayvan çalışmasında, TME'lerinde bilateral olarak artrit oluşturulmuş ve MTX'in etkileri değerlendirilmiştir. Araştırmada, MTX'in sistemik olarak uygulanmasının, tavşan TME'nin enflamatuar süreci üzerinde olumlu etkiye sahip olduğu ancak artrit belirtilerinin tamamen ortadan kaldırılamadığı bildirilmiştir. ${ }^{37}$ Araştırmamızda bu çalışmaların 
sonuçlarından farklı olarak MTX kullanan ve kullanmayan olgular arasında ağrı, ses, kısıtlı hareket, retrognati ve anterior open-bite görülme oranları açısından istatistiksel olarak anlamlı bir farklıık bulunmamıştır. TME tutulumunun değerlendirilmesinde araştırmamızda, TME'nin klinik muayene bulguları değerlendirilmiş, radyografik olarak bir değerlendirme yapılmamıştır. Sonuçların örtüşmemesinin sebebinin, TME tutulumu değerlendirme yöntemlerinin farklı olması ile ilgili olduğu düşüncesindeyiz.

JIA'lı hastalar için geçerli özel bir muayene protokolü yoktur. Hastanın yaşı, şikayetleri ve TME tutulumu ile hastalığın aktivitesi göz önünde bulundurularak her bireye göre ayrı değerlendirilmesi önerilmiştir. ${ }^{38} \mathrm{JIA}^{\prime} \mathrm{l} ı$ hastaların orofasiyal muayenesi için klinik uygulamada ve ileride yapılacak çalışmalar için standardize edilmiş veri toplamada kullanılmak üzere, uluslararası görüş birliği oluşturabilmek amacı ile öneriler geliştirmek üzere 2017 yılında bir makale yayınlanmıştır. Bu makalede; 1) tıbbi geçmiş, 2) orofasiyal semptomlar, 3) kas ve temporomandibular eklem fonksiyonu, 4) orofasiyal fonksiyon ve 5) dentofasiyal büyüme olmak üzere 5 alanı değerlendirmek için öneriler geliştirilmiştir. Yapılan araştırmalar, tıbbi öykü ve fizik muayene sınucunda ortaya çıkan klinik semptomlar ile TME artriti arasındaki ilişkiyi açıkça ortaya koysa da, bu klinik bulgular, TME inflamasyonunun varlığının kesin olarak teşhis edilmesinde yetersiz kalmaktadır. Bununla birlikte, klinik muayene; hastanın rahatsızığının, orofasyal disfonksiyonun ve dismorfik mandibular gelişimin uzun dönemli takibinde önemli rol oynamaktadır. Bu nedenlerle TME muayenesi, JIA' lı hastaların klinik değerlendirilmesinde kritik bir rol oynamaktadır. ${ }^{39}$

\section{SONUÇ}

Ağız sağlığının iyi olması, çürük ve diş eti hastalıklarının azaltılmasında önem taşımaktadır. JIA' nın sonuçları farklılıklar göstemektedir ve birçok hastada ciddi derecede morbidite olasılığına neden olabimektedir. Bu komplikasyonların listesine kötü ağız sağlığı riski de eklenmelidir. Bununla birlikte, tüm JIA' lı çocukların ağız hijyeninin kötü olduğu genellemesi yapılmamalıdır. Özellikle yüksek risk altındaki çocukları tanımlamak ve hastalar ve aileleri tarafından alınması muhtemel önlemlerin etkinliğini ve maliyet etkinliğini araştırmak için kapsamlı çalışmalara intiyaç vardır.

\section{KAYNAKLAR}

1.Barr DGD, Crofton PM, Goel KM. Disorders of bone, joints and connective tissue. In: Campbell AGM, Mclntosh $\mathrm{N}$, editors. Textbook of pediatrics, 5th edition. Edinburgh: Churchill Livingstone; 1998.p.1544-1615.

2.Özen S, et al. Prevalence of JCA and familial Mediterranean fever in Turkey: A field study. J Rheumatol 1998; 25: 2445-2449.
3.Kasapçopur Ö, Arısoy N. Jüvenil idyopatik artrit. Türk Pediatri Arşivi 2003; 38: 8-19.

4.Wipff J, Sparsa L, Lohse A, Quartier P, Kahan A, Deslandre CJ. Impact of juvenile idiopathic arthritis on quality of life during transition period at the era of biotherapies. Joint Bone Spine 2016; 83: 69-74.

5. Arabshahi B, Cron RQ. Temporomandibular joint arthritis in juvenile idiopathic arthritis: the forgotten joint. Curr Opin Rheumatol 2006; 18: 490-495.

6.Mandall NA, et al. Juvenile idiopathic arthritis (JIA): a screening study to measure class II skeletal pattern, TMJ PDS and use of systemic corticosteroids. J Orthod 2010; 37: 6-15.

7.von Bremen J, Ruf S. Juvenile idiopathic arthritis and now: a systematic literature review of changes in craniofacial morphology. J Orofac Orthop 2012; 73: 265-276.

8. Ruth NM, Passo MH. Juvenile idiopathic arthritis: management and therapeutic options. Ther Adv Musculoskelet Dis 2012; 4: 99-110.

9.Walton AG, Welbury RR, Thomason JM, Foster HE. Oral health and juvenile idiopathic arthritis: a review. Rheumatology (Oxford) 2000; 39: 550-555.

10.Walton AG, Welbury RR, Foster HE, Wright WG, Thomason JM. Sialochemistry in juvenile idiopathic arthritis. Oral Dis 2002; 8: 287-290.

11.Feres de Melo AR, Ferreira de Souza A, de Oliveira Perestrelo B, Leite MF. Clinical oral and salivary parameters of children with juvenile idiopathic arthritis. Oral Surg Oral Med Oral Pathol Oral Radiol 2014; 117: 75-80.

12.de Oliveira Perestrelo B, Feres de Melo AR, de Sant'Anna GR, Leite MF. Compromised salivary parameters of children with juvenile idiopathic arthritis. Oral Surg Oral Med Oral Pathol Oral Radiol 2016; 121: 262-268.

13.Welbury RR, Thomason JM, Fitzgerald JL, Steen IN, Marshall NJ, Foster HE. Increased prevalence of dental caries and poor oral hygiene in juvenile idiopathic arthritis. Rheumatology (Oxford) 2003; 42: 1445-1451.

14.World Health Organization (1997) Oral Health Survey: Basic Methods. 4th Edition, Geneva.

15.Savioli C, Silva CA, Ching LH, Campos LM, Prado EF, Siqueira JT. Dental and facial characteristics of patients with juvenile idiopathic arthritis. Rev Hosp Clin Fac Med Sao Paulo 2004; 59: 93-98.

16. Hu Y, Billiau AD, Verdonck $A$, Wouters $C$, Carels $C$. Variation in dentofacial morphology and occlusion in juvenile idiopathic arthritis subjects: a case-control study. Eur J Orthod 2009; 31: 51-58.

17.Yilmaz M, Kendirli SG, Altintas DU, Karakoc GB, Inal A, Kilic M. Juvenile idiopathic arthritis profile in Turkish children. Pediatr Int 2008; 50: 154-158.

18.Johnson K, Gardner-Medwin J. Childhood arthritis: classification and radiology. Clin Radiol 2002; 57: 47-58. 19.Ahmed N, Bloch-Zupan A, Murray KJ, Calvert M, Ro- 
berts GJ, Lucas VS. Oral health of children with juvenile idiopathic arthritis. J Rheumatol 2004; 31: 1639-1643.

20.Leksell E, Ernberg M, Magnusson B, Hedenberg-Magnusson B. Intraoral condition in children with juvenile idiopathic arthritis compared to controls. Int J Paediatr Dent 2008; 18: 423-433.

21.Walton AG, Welbury RR, Foster HE, Thomason JM. Juvenile chronic arthritis: a dental review. Oral Dis 1999; 5: 68-75.

22. Aliko A, Alushi $A$, Tafaj $A$, Lela F. Oral mucosa involvement in rheumatoid arthritis, systemic lupus erythematosus and systemic sclerosis. Int Dent J 2010; 60: 353-358. 23. Havemose-Poulsen A, Westergaard J, Stoltze K, Skjø$\mathrm{dt} \mathrm{H}$, Danneskiold-Samsøe B, Locht $\mathrm{H}$ et al. Periodontal and hematological characteristics associated with aggressive periodontitis, juvenile idiopathic arthritis, and rheumatoid arthritis. J Periodontol 2006; 77: 280-288.

24.Scolozzi P, Bosson G, Jaques B. Severe isolated temporomandibular joint involvement in juvenile idiopathic arthritis. J Oral Maxillofac Surg 2005; 63: 1368-1371.

25.Te Veldhuis EC, Te Veldhuis AH, Koudstaal MJ. Treatment management of children with juvenile idiopathic arthritis with temporomandibular joint involvement: a systematic review. Oral Surg Oral Med Oral Pathol Oral Radiol 2014; 117: 581-589.

26.Selvi Kuvvetli S, Sandallı N. Çocuklarda ve genç erişkinlerde temporomandibular rahatsızlıklar: Literatür derlemesi. Atatürk Üniv. Diş Hek. Fak. Derg 2007; 2: 1-9.

27. Küseler A, Pedersen TK, Herlin T, Gelineck J. Contrast enhanced magnetic resonance imaging as a method to diagnose early inflammatory changes in the temporomandibular joint in children with juvenile chronic arthritis. J Rheumatol 1998; 25: 1406-1412.

28. Kristensen KD, Stoustrup $P$, Küseler $A$, Pedersen TK, Twilt M, Herlin T. Clinical predictors of temporomandibular joint arthritis in juvenile idiopathic arthritis: A systematic literature review. Semin Arthritis Rheum 2016; 45: 717-732. 29.Abramowicz S, Susarla HK, Kim S, Kaban LB. Physical findings associated with active temporomandibular joint inflammation in children with juvenile idiopathic arthritis. J Oral Maxillofac Surg 2013; 71: 1683-1687.

30.Twilt $M$, Mobers $S M$, Arends LR, ten Cate $R$, van Suijlekom-Smit L. Temporomandibular involvement in juvenile idiopathic arthritis. J Rheumatol 2004; 31: 1418-1422.

31.Küseler A, Pedersen TK, Gelineck J, Herlin T. A 2 year followup study of enhanced magnetic resonance imaging and clinical examination of the temporomandibular joint in children with juvenile idiopathic arthritis. J Rheumatol 2005; 32: 162-169.

32. Frid $P$, Nordal $E$, Bovis F, Giancane G, Larheim TA, Rygg $M$ et al. Temporomandibular Joint Involvement in Association With Quality of Life, Disability, and High Disease Activity in Juvenile Idiopathic Arthritis. Arthritis Care
Res (Hoboken) 2017; 69: 677-686.

33.Twilt $M$, Schulten AJ, Verschure $F$, Wisse $L$, Prahl-Andersen B, van Suijlekom-Smit LW. Long-term followup of temporomandibular joint involvement in juvenile idiopathic arthritis. Arthritis Rheum 2008; 59: 546-552.

34. Kasapçopur Ö, Barut K. Jüvenil idiyopatik artritte tedavi ve yeni tedavi seçenekleri. Türk Ped Arş 2015; 50: 1-10. 35. Ince DO, Ince A, Moore TL. The effect of methotrexate on the temporomandibular joint in polyarticular juvenile rheumatoid arthritis patients. J Clin Rheumatol 1999; 5: 320-5.

36.Ince DO, Ince A, Moore TL. Effect of methotrexate on the temporomandibular joint and facial morphology in juvenile rheumatoid arthritis patients. Am J Orthod Dentofacial Orthop 2000; 118: 75-83.

37.Rafayelyan S, Meyer P, Radlanski RJ, Minden K, Jost-Brinkmann PG, Präger TM. Effect of methotrexate upon antigen-induced arthritis of the rabbit temporomandibular joint. J Oral Pathol Med 2015; 44: 614-621.

38. Niibo P, Pruunsild C, Voog-Oras Ü, Nikopensius T, Jagomägi T, Saag M. Contemporary management of TMJ involvement in JIA patients and its orofacial consequences. EPMA J 2016; 7:12.

39.Stoustrup $P$, Twilt $M$, Spiegel $L$, Kristensen KD, Koos $B$, Pedersen TK et al. Clinical Orofacial Examination in Juvenile Idiopathic Arthritis: International Consensus-based Recommendations for Monitoring Patients in Clinical Practice and Research Studies. J Rheumatol 2017; 44: 326333. 